\title{
EBIC AND CL STUDY OF LASER DEGRADATION
}

\author{
P. HENOC, R. BENETTON-MARTINS and B. AKAMATSU \\ Centre National d'Etudes des Télécommunications, Laboratoire de Bagneux, 196 Av. Henri \\ Ravéra, F-92120 Bagneux, France
}

\begin{abstract}
The first stages of $\mathrm{Ga}(\mathrm{Al}) \mathrm{As}$ laser degradation are studied by means of $\mathrm{CL}$ and EBIC measurements on cleaved facets of devices. Degradation by electron beam irradiation is compared to degradation during working. It is concluded that degradation starts in the depleted region with a loss of Si dopant electrical activity. Local degradation speed for $\mathrm{Ga}(\mathrm{Al}) \mathrm{As}$ epitaxial layers grown on either $\mathrm{GaAs}$ or $\mathrm{Si}$ substrates are compared.
\end{abstract}

\section{1.- Introduction,}

The degradation of opto-electronic lasers can arise from phenomena of different origins $[1,2,3,4]$. It may be crystalline defects related to substrate quality or epitaxial layer growth. It may be punctual defects or strains introduced during the technological stages of device fabrication. The precise region where the degradation starts has been determinated by means of the simultaneous measurement of the EBIC and $\mathrm{CL}$ signals in a Scanning Electron Microscope (SEM). We studied a Ga(Al)As GRIN-SCH (graded-index separate-confining heterostructure) laser with a single quantum well inserted in it $[5,6,7]$. The presence of extended defects is not necessary for initiating degradation. We show that the aging is related to a loss of electrical activity of the Si dopant in the depleted zone of the diode. Moreover, this study, which concerns the beginning evolution of the laser characteristics, shows that the active layer has no responsability in the initial degradation procedure.

\section{2.- Experimental set-up.}

Two types of lasers $\mathrm{GaAs}, \mathrm{Ga}(\mathrm{Al}) \mathrm{As}$ have been studied: the epitaxies of the lasers are done on substrates of either GaAs $\mathrm{n}+$ or $\mathrm{Si} n+[8,9,10]$. The active layer is a quantum well, $20 \mathrm{~mm}$ thick in the first case and $60 \mathrm{~A}$ thick in the second one. In both types of lasers the two confining layers are $200 \mathrm{~nm}$ thick and made of graded gap $\mathrm{Ga}_{(1-x)} \mathrm{Al}_{x} \mathrm{As}$ ( $\mathrm{x}$ varying from 0,2 to 0,5 ). The samples were grown by metal organic vapour deposition (MOCVD), except the buffer layer on the $\mathrm{Si}$ substrate, which was grown by molecular beam epitaxy (MBE). The two structures are shown on Fig.1. 


\begin{tabular}{|c|c|}
\hline$G_{a A s}$ & $\left(p^{\circ}\right) 10.64 \mathrm{~m}$ \\
\hline 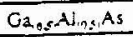 & $\left(p^{\circ}\right)(1.14 \mathrm{~m})$ \\
\hline 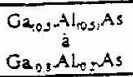 & $(n)(2000 \AA)$ \\
\hline Ga4s & (60) \\
\hline 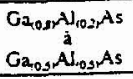 & $(n)(2000 A)$ \\
\hline Geros.Avos As & $\left(\mathrm{n}^{\top}\right)(1.1 \mathrm{um})$ \\
\hline 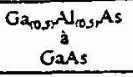 & $\left(\mathrm{n}^{+}\right)(0.5 \mu \mathrm{m})$ \\
\hline GaAs(MBE) & $\left(\mathrm{n}^{7}\right)(0.64 \mathrm{~m})$ \\
\hline $\mathrm{Si}$ & $\left(n^{*}\right)$ \\
\hline
\end{tabular}

\begin{tabular}{|c|c|c|}
\hline GaAs & \multicolumn{2}{|l|}{$\left(p^{*}\right)(0.6 \mu \mu \pi)$} \\
\hline 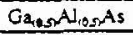 & $\left(p^{\circ}\right)(1.2 \mu \mathrm{m})$ & \\
\hline 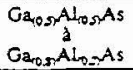 & (n) $(2000 \mathrm{~A})$ & $\mid \begin{array}{l}G \\
R \\
I\end{array}$ \\
\hline GaAs & $(200 \mathrm{~A})$ & $\mathrm{N}$ \\
\hline 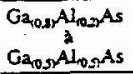 & $(\mathrm{n})(2000 \AA)$ & $\begin{array}{l}\mathrm{S} \\
\mathrm{C} \\
\mathrm{H} \\
\mathrm{H}\end{array}$ \\
\hline Ga, A A & $\left(\mathrm{n}^{\circ}\right)(2.0 \mu \mathrm{m})$ & \\
\hline GaAs & $(\mathrm{n})(0.8 \mu \mathrm{m})$ & \\
\hline GaAs (Subst) & (n) & \\
\hline
\end{tabular}

Figure 1: Ga(Al)As GRIN-SCH lasers:

$$
\begin{aligned}
& a \text { - with Si substrate } \\
& b \text {-with GaAs substrate }
\end{aligned}
$$

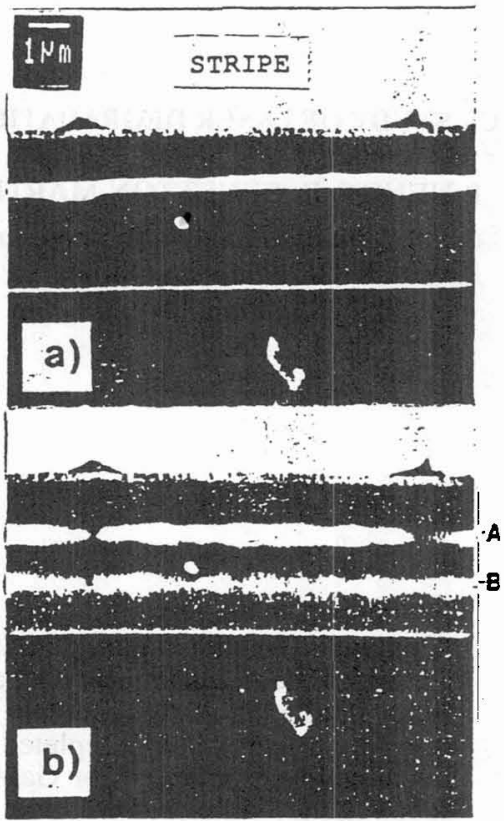

Figure 2: ES images of the cleaved facet of a degraded GRIN-SCH laser: EBIC (a) and $C L(b)$ images are superimposed

The Fig.2 presents SEM micrographs of the cleaved face of the partially degraded laser, grown on Si substrate. The EBIC signal on Fig.2a and the wavelength unfiltered CL signal on Fig.2b are superimposed to the secondary electron (SE) SEM micrograph. By means of this SE signal it is possible to locate precisely the $\mathrm{Si} / \mathrm{GaAs}$ interface. This is very important for quantitative evaluations of the EBIC and CL signals, the amplitudes of which are a function of the electron beam impact point. In Fig. $2 \mathrm{~b}$, one can see two brigth bands. "A" corresponds to the active layer emission; it is inhomogeneous and its minimum is located under the edge of the stripe. This stripe was defined by localized proton implantation. The intensity of the band " $B$ " is weaker than the " $A$ " one and the maximum occurs when the impact point of the electron beam is near the interface $\mathrm{Ga}_{0,5} \mathrm{Al}_{0,5} \mathrm{As} /$ thick graded composition layer. Moreover, the peak emission wavelength corresponds to GaAs. This phenomenon can be explained: in a graded composition layer of $\mathrm{Ga}(\mathrm{Al}) \mathrm{As}$, obtained by MOCVD, uncontrolled multiple quantum wells may be observed.

On Fig.2a, the most important feature is that the EBIC signal extends towards the substrate, just in the same region where the luminescence of the active layer decreases. The quantitative evaluations of EBIC and CL signals are shown in Fig.3; they are obtained by scanning, perpendicularly to the interfaces, a cleaved facet of the device, but only on the $p-n$ interface plus the GRIN-SCH and after different electron beam irradiation doses. 


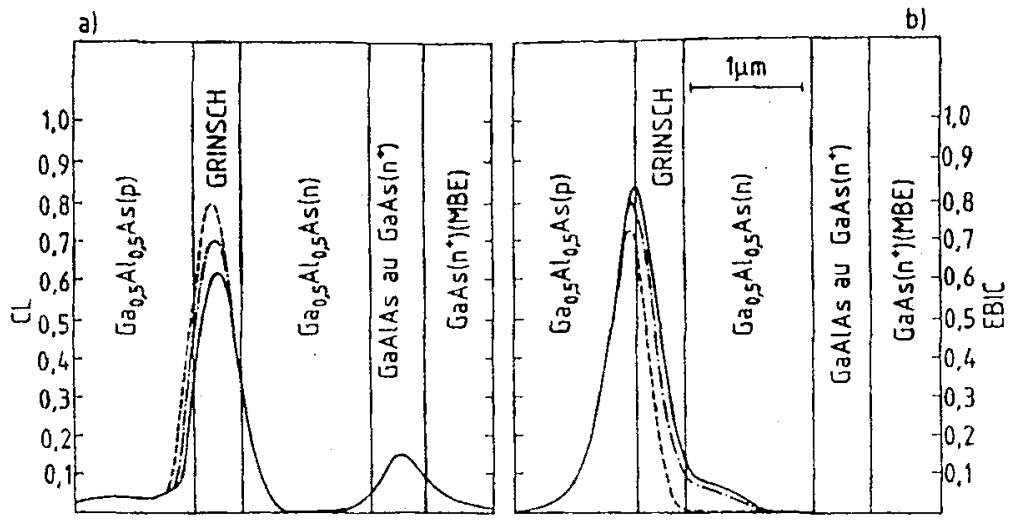

Figure 3: CL and EBIC profiles on a cleaved surface of the laser:

-.. initial state

-... after electronic irradiation

As it can be seen from the figure, when the dose increases, the ligth emission decreases and the EBIC signal increases, both continuously, and a "tail" appears on the n side, as it has been observed locally in Fig.2a. Similar irradiation doses on the buffer layer, on the nearest graded composition layer and on the $\mathrm{Ga}_{0,5} \mathrm{Al}_{0,5} \mathrm{As}$ have no similar effects. As those regions are the most dislocated one it appears that the part taken by the extended defects is negligible.

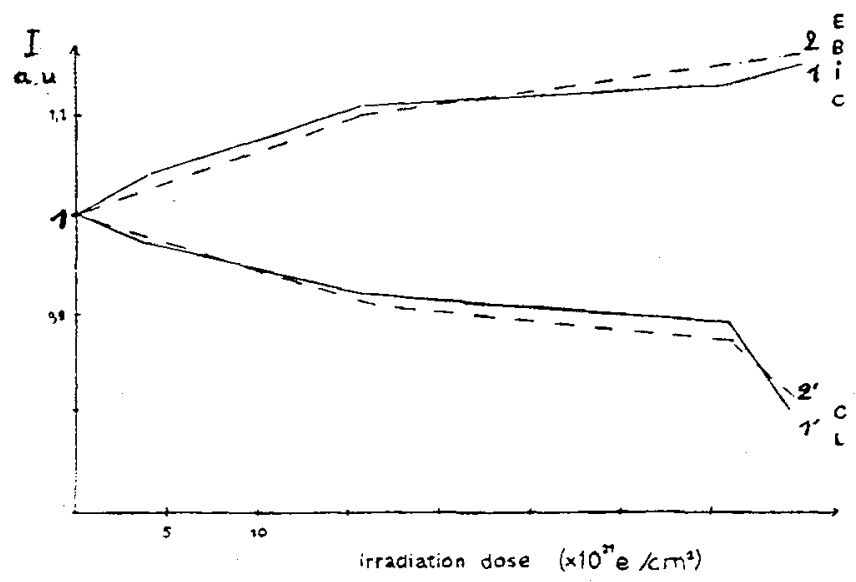

Figure 4: Variation of EBIC and CL maxima related to electron irradiation dose $\left(l, l^{\prime}\right)$ and to working time of the laser $(2,2$ ').

The Fig.4 shows first (curves 1,1') the maxima evolution of the EBIC and CL signals as a function of the electron irradiation dose, when the scanning of the electron beam covers the limited region: electrical junction plus GRIN-SCH. It shows second (curves 2,2'), the maxima evolution of the same signals, but as a function of the working time of the laser. In this case the diode was in situ directly biased, with an external polarization source. As the graphs $\left(1,1^{\prime}\right)$ and $\left(2,2^{\prime}\right)$ are very similar, it is then possible to obtain a simulation of the degradation occuring during operation, when an external current is applied to the GaAs laser 
device, by a mere electron irradiation. With this method we were abble to observe the degradation of chosen regions. The spatial resolution is then given in one direction by the GRIN-SCH depth and in the other one by the fast electron-matter interaction $(<1 \mu \mathrm{m})$.

An important information is that the initial profiles of EBIC can be recovered by direct polarization of the diode [11], the intensity of the bias depending on the irradiation dose, that is on the degradation state. The conclusion is that the evolution of the EBIC and CL signals, due to the degradation, indicates a modification of the electrical field, near the $\mathrm{p}-\mathrm{n}$ junction.

The Fig.5 gives the band diagram calculated [12] in three conditions:

-doping level of the $n$ region: $10^{17} \mathrm{~cm}^{-3}$; without polarization

-doping level of the $n$ region: $5.10^{16} \mathrm{~cm}^{-3}$; without polarization

-doping level of the $\mathrm{n}$ region: $5.10^{16} \mathrm{~cm}^{-3}$; with direct polarization: $\mathrm{V}=1$ Volt.

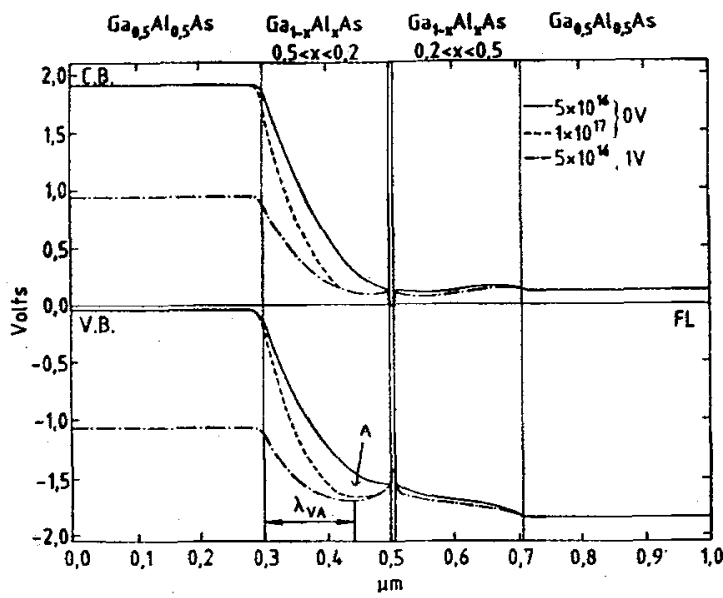

Figure 5: Calculated band diagrams of a GRIN-SCH structure:

- V $=0 . V$.; doping level $n: 5.10^{16} \mathrm{~cm}^{-3}$

- . V V = O.V.; doping level $n: 1.10^{17} \mathrm{~cm}^{-3}$

-...V V = I.V.; doping level $n: 5.10^{16} \mathrm{~cm}^{-3}$

The graded gap in the depleted region gives a minimum $A$ in the valence band. The distance from the electrical junction of this "virtual anode", $\lambda_{v_{A}}$, is a function of the doping level. For the MEB analysis this anode is a wall dividing two fields for holes. Holes generated by the electron beam between $A$ and the $p-n$ junction drift towards this junction and produce EBIC. Those generated between $\mathrm{A}$ and the quantum well drift towards the active layer and produce, there, luminescence by radiative recombination with electrons trapped in it.

A virtual anode shift towards the substrate can explain an EBIC increase and a CL decrease, which are observed in the degradation first stage, and second, the possibility of signal recovering with an external polarization, which replaces $\lambda_{v A}$ at its initial position (Fig.5). Therefore, it seems that the degradation physical process is a loss of electrical activity of the $\mathrm{Si}$ dopant. Another reason justifies this assertion: these degradation effects are observed only when the electron irradiation is located in the depleted region. In this region $\mathrm{Si}^{+}$ions are no more screened by free carriers and there is a coulombic attraction between $\mathrm{Si}^{+}$ions and native defects like $\mathrm{V}_{\mathrm{Ga}}{ }^{-}$, giving a complexe $[13,14]$ :

$$
\mathrm{Si}^{+}+\mathrm{V}_{\mathrm{Ga}}^{-}-->\mathrm{SiV}_{\mathrm{Ga}}
$$


This deep level is able either to trap carriers for non radiative recombinations, or to enhance optical absorption to give local heating.

To give some quantitative measurements of the degradation stage, that is of the virtual anode position, and as the layer thicknesses are always smaller than the electron-hole pair generation volume, it is necessary to use an accurate generation function modulated by the beam spot size [15]. For this purpose, we use our three gaussian function. For an accelerating voltage of $7 \mathrm{keV}$. and a beam current of $2 \mathrm{nA}$, the beam spot size is of about $60 \mathrm{~nm}$ [16]. The Fig.6 shows the maxima variations of EBIC and CL signals calculated as a function of the virtual anode position A. And this for two quantum well capture cross sections $\sigma_{c}$ values. This latter parameter is necessary to justify the EBIC tail observed in degraded structures, as shown on Fig.3.

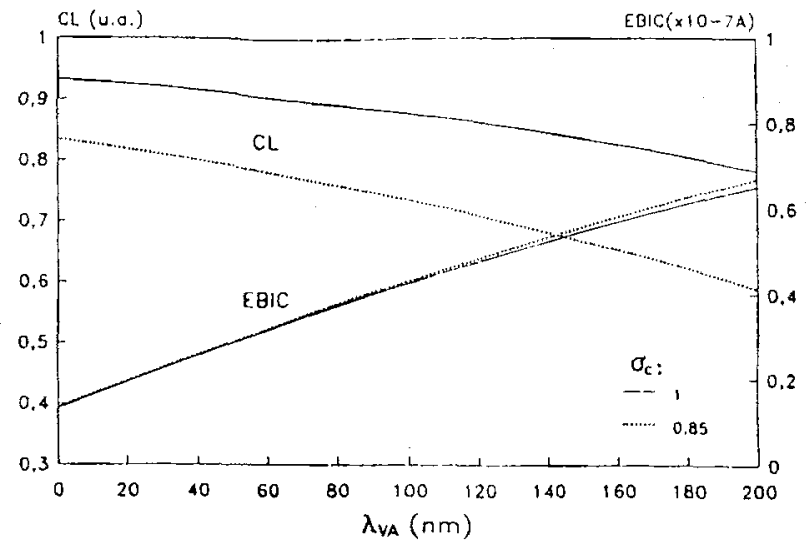

Figure 6: EBIC and $C L$ maxima related to the $\lambda_{V A}$ position, for two values of $\sigma c$.

Table 1 gives the best fit for $\lambda_{\mathrm{VA}} \sigma_{\mathrm{c}}$ and $\mathrm{N}_{\mathrm{df}}$ (new concentration of ion donors, after degradation) with EBIC and CL profiles after various irradiation doses, and this for GaAs/GaAs and $\mathrm{GaAs} / \mathrm{Si}$ lasers; in the latter case two regions are observed: one is situated under the stripe, and the other under the proton implanted surface.

Table 1: Evolution of $\lambda_{V_{A}}, \sigma_{c}$ and $N_{d f}$, related to the irradiation dose, for implanted and non implanted GaAs/GaAs and GaAs/Si lasers. $\left(a: \Delta \eta_{C L}=0,95 ; \quad b: \Delta \eta_{C L}=0,93\right.$ )

\begin{tabular}{|c|c|c|c|c|}
\hline Sample & $\begin{array}{l}\text { Dose } \\
\left(\mathrm{e}^{-} / \mathrm{cm}^{-2}\right)\end{array}$ & $\begin{array}{c}\lambda_{V A}(\mathrm{~nm}) \\
( \pm 5)\end{array}$ & $\sigma_{t}$ & $\begin{array}{c}N d g \\
\left(\mathbf{x} 10^{16} \mathrm{~cm}^{-3}\right)\end{array}$ \\
\hline$\underset{\text { (implanted) }}{\mathbf{G a A s} / \mathbf{S i}}$ & $\begin{array}{c}4 \times 10^{21} \\
9 \times 10^{21} \\
2,25 \times 10^{22} \\
5,25 \times 10^{22}\end{array}$ & $\begin{array}{c}140 \\
180 \\
>195 \\
>195\end{array}$ & $\begin{array}{c}0,92 \\
0,89 \\
0,86 \mathrm{a} \\
\ldots .\end{array}$ & $\begin{array}{c}10 \pm 1,5 \\
6,5 \pm 1,0 \\
<5,0 \\
<5,0\end{array}$ \\
\hline $\begin{array}{c}\text { GaAs/Si } \\
\text { (non implanted) }\end{array}$ & $\begin{array}{c}8 \times 10^{21} \\
1,5 \times 10^{22} \\
2,25 \times 10^{22} \\
5,25 \times 10^{22}\end{array}$ & $\begin{array}{c}140 \\
175 \\
195 \\
>195\end{array}$ & $\begin{array}{l}0,95 \\
0,93 \\
0,90 a \\
0,87 b\end{array}$ & $\begin{array}{c}10 \pm 1,5 \\
7,0 \pm 1,3 \\
5,5 \pm 1 \\
<5,0\end{array}$ \\
\hline GaAs/GaAs & $\begin{array}{c}1,5 \times 10^{22} \\
2,25 \times 10^{22} \\
60 \times 10^{22}\end{array}$ & $\begin{array}{c}85 \\
105 \\
160\end{array}$ & $\begin{array}{l}1,00 \\
1,00 \\
0,95\end{array}$ & $\begin{array}{c}30 \pm 4,0 \\
20 \pm 3 \\
8,9 \pm 1,3\end{array}$ \\
\hline
\end{tabular}

To obtain the same degradation state, the irradiation dose has to be greater for GaAs/Si under the proton implanted surface than for GaAs/Si under the stripe, and it has to be even greater for $\mathrm{GaAs} / \mathrm{GaAs}$ lasers. 
It is interesting to see that for the same doping level after degradation, $\sigma_{\mathrm{c}}$ has the same value for the three lasers. It is only a function of the valence band profile at the vicinity of the quantum well [17].

With irradiation doses greater than $2.10^{22} \mathrm{e}^{-} \mathrm{cm}^{-2}$, the EBIC profiles fit well with $\sigma_{\mathrm{c}}$ and $\lambda_{\mathrm{VA}}$ adjustments. But CL losses are too high. Then, one must adjust the internal efficiency $\eta$ of the active layer. In this last case, it seems that other degradation phenomena occur. Non radiative recombinations on deep levels produce local heating, extended defect motions, and multiplications, both towards and in the active layer $[18,19]$.

\section{3.-Bibliography:}

/1/HUTCHINSON,P.W. and DOBSON,P.S., Philos. Mag., Al(4) (1980) 601

/2/ESWAR,C., MADHAVA-MENON, PETROFF,P.M. and WATERS,R.G., Appl. Phys. Lett., 54 (26) (1989) 2683

/3/PETROFF,P.M., MILLER,R.C., GOSSARD,A.C. and WIEGMANN,W., Appl. Phys. Lett., 44 (2) (1984) 217

/4/IMAI,H., ISOZUMI,K. and TAKUSAGAWA,M., Appl. Phys. Lett., 33 (4) (1978) 330

15/KRAKOWSKI,M., HIRTZ,P., BLONDEAU,R., HERSEE,S.D.,BALDY,M., DE CREMOUX,B. and DUCHEMIN,J.P., Electr. Let., 19 (25/26) (1983) 1082

/6/TSANG,W.T., Appl. Phys. Lett. 39 (2) (1981) 134

П/FELDMANN,J., PETER,G., GOBEL,E.O., LEO,K., POLLAND,H.J., PLOOG,K., FUJIWARA,K. and NAKAYAMA,T., Appl. Phys. Lett. 51 (4) (1987) 226

/8/CHARASSE,M.N., BARTENLIAN,B., GERARD,B., HIRTZ,J.P., LAVIRON, M., DE PARSCAU,A.M., DEREVONKO,M. and DELAGEBEAUDEUF D., Jap. J. Appl. Phys. 28 (11) (1989) L1896

19/CHEN,H.Z., GHAFFARI,H., WANG,H., MORKOC,H. and YARIV,A., Appl. Phys. Lett. 51 (17) (1987) 1320

/10/VAN GIESON,E., MEIER,H.P., HARDER,C., BUCHMANN,P., WEBB,D. and WALTER,W., J. Vac. Sci. Technol. B7 (2) (1989) 405

/11/MARTINS,R.B., HENOC,P., AKAMATSU,B., BARTENLIAN,G. and CHARASSE,M.N., J. Appl. Phys. 68 (3) (1990) 937

/12/SIBILE,A., PALMIER,J.F., WANG,H. and MOLLOT,F., Phys. Rev. Lett. 64 (1990) 52 /13/MAGUIRE,J., MURRAY,R. and NEWMAN,R.C., Appl. Phys. Lett. 50 (9) (1987) 516 /14/ISHIKAWA,T., INATA,T., KONDO,K., and SHIBATOMI,A., El. Lett. 22 (4) (1986) 189

/15/AKAMATSU,B., HENOC,P. and MARTINS,R.B., J. Microsc. Spectrosc. Electron. 14 (2) (1989) 12a

/16/BENETTON-MARTINS,R., Thèse, Univ. Paris-XI,(1991); CNET, 92220 BAGNEUX, FRANCE

/17/POLLAND,H.J., ROTHER,K., PLOOG,K., FELDMAN,J., PETER,G., GOBEL,E.O., FUJIWARA,K., NAKAYAMA,T., and OHTA,Y., Phys. Rev. B 38 (11 (1988) 7635

/18/KIMMERLING,L.C., Solid State Electron. 21 (1978) 1391

/19/HUTCHINSON,P.W., ROBSON,P.S., WAKEFIELD,B. and O'HARA,S., in op. cit. 1413 